regulation of enzyme activity and synthesis together with tissue synthesis and repair within the body. A deeper understanding of these topics and, in particular of the control mechanisms operating on the primary biochemical pathways, would appear to be necessary for more precise definition of protein and amino acid needs. At present estimates vary by a factor of two, or more. Closer evaluations are clearly desirable, the more so when calculations are made of the quantities of food, and consequent effort, needed to satisfy demand for whole populations. Provision of only I $\mathrm{g}$ of $\mathrm{N} \times 6.25$ per day to each of a population of $5^{\circ}$ million people for instance would entail production of about $2 \times 10^{5}$ tons of cereal, $\mathrm{I} \times 1 \mathrm{O}^{5}$ tons of legume, $5 \times 10^{4}$ tons of skim-milk solids or $6 \times 10^{7}$ broiler fowls per year-all requiring a considerable investment in land, labour and materials.

This example indicates the magnitude of the supplies that may be needed and hints at the economic and social problems that must be overcome if such quantities of extra food are to be produced and if the populations at risk are to be provided with the funds to pay for it. Sources of protein other than the traditional foods might well significantly contribute to man's needs. For this reason, therefore, we are fortunate to be able to hear at this meeting of the ways in which protein resources could be greatly increased, by the improvement of some and the better use of others, together with development of entirely novel products.

REFERENCE

Advisory Committee on the Application of Science and Technology to Development (r968). In International Action to Avert the Impending Protein Crisis, p. 40. New York: United Nations Organization.

The absorption of protein from the intestine

By K. J. CARpenter, School of Agriculture, University of Cambridge

This paper was prepared at very short notice and no written version will be published.

\title{
Adaptation of mammalian protein metabolism to amino acid supply
}

\author{
By Hamish N. Munro, Physiological Chemistry Laboratories, \\ Department of Nutrition and Food Science, Massachusetts Institute of Technology, \\ Cambridge, Massachusetts
}

\section{Introduction}

The metabolism of the animal is equipped to adapt to changes in both the internal and the external environment. Among internal factors are activity versus rest and sleep, and the menstrual cycle in the case of the female. Metabolism must also respond to variations in the external environment, such as heat and cold, and notably 